\title{
Sustainable resorts: learning from the 2004 tsunami
}

\author{
Renato Garcia, Stephen Siu-Yu Lau and K.W. Chau \\ Faculty of Architecture, University of Hong Kong, Hong Kong, \\ People's Republic of China \\ Rachadaporn Kanitpun
}

Faculty of Architecture, Thammasat University, Pathumthani, Thailand

Yoichi Shimatsu

AI Consultants, Bangkok, Thailand

Peter Grunder

Paris Lund University, Sweden, France

Rosena Koo and Baharuddin

Faculty of Architecture, University of Hong Kong, Hong Kong, People's Republic of China

\begin{abstract}
Purpose - Given the extensive destruction resulting from the devastating 2004 Indian Ocean tsunami that destroyed and damaged resort complexes in southern Thailand, the purpose of this research paper is to focus on the planning of architecture of resorts in two layers: the relationship of structures and land use to the natural environment, and the identification of specific design flaws that resulted in the loss of life.

Design/methodology/approach - An international collaborative effort led to site visits by our research team to the hardest-hit resort areas of Khao Lak, Takua Pa, and Ko Phi Phi on December 29, 2004-January 6, 2005, and in February 2005. The research team had direct contact with the adverse effects of the tsunami and gained insightful understanding on how structures and faulty architectural designs worsened the disaster and obstructed the process of saving lives. Analysis of these effects were then compiled and used to underpin subsequent proposals for resort reconstruction to minimize future destruction which may result from such calamities.

Findings - Close scrutiny and subsequent analysis of various factors which magnified the destruction and damage caused by the tsunami resulted in action plan proposals for sustainable resort development aimed at avoiding a repeat of the tragedy. These include responses to site, architecture, structures, building services and landscaping. More specifically proposals were made on issues of relocation, modifications of design flaws, introduction of escape routes, safer rooms, restoration of waterways, co-generation, tree plantation and incorporation of natural landscape.

Research limitations/implications - Most of the information and data were gathered first hand at the location mentioned. More studies are needed to reinforce and further validate the proposed measures as generally applicable in similar locations.

Originality/value - An action plan outlining measures aimed at minimizing damage from such natural disasters could provide a useful resource in future planning of resorts in tsunami prone locations.

Keywords Sustainable design, Natural disasters, Tidal waves, Thailand

Paper type Research paper
\end{abstract}
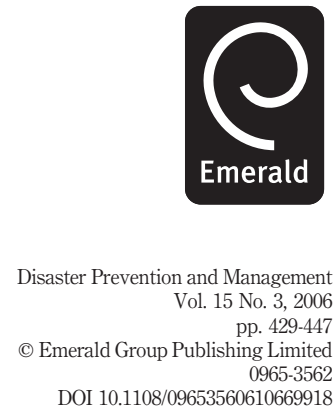
DPM

15,3

430

\section{Introduction: unsustainable tourist facilities led to deaths}

Over the past two decades, south Thailand's beach scene spawned a shortsighted consumerist economy of convenience and fast money. Despite the obvious warning signs the overcrowding of hotels, restaurants, and shops along the seafront, the improper planning of resorts along narrow strips, and the unstable structures on sandy beaches - the tourism industry created "an accident waiting to happen" (Plate 1). If the tourist industry had used proper planning for oceanfront safety and followed sustainable architecture principles in line with environmental realities, the tsunami would not have resulted in so many deaths and so much property loss and harm to Thailand's international image.

The Boxing Day tsunami sent a clear signal to national and local governments, developers, and planners to adopt the principles of environmentally sustainable development for future planning. Environmental viability/vulnerability factors of built structures within the shoreline ecology are among the major concerns for the reconstruction and building of tourism facilities. Resort areas must be safely sited to minimize potential threats to locals and visitors. Physical safety measures and a consequent psychological sense of security are key factors in stimulating people's interest in visiting the Indian Ocean coast and, at the same time, sustainable architecture can enhance the natural beauty of south Thailand.

The tsunami was not a "one-off" event, but a sign of things to come. Global climate change is raising sea levels, stirring up more powerful monsoons and cyclones, and flooding rivers. Seismic activity, including earthquakes, volcanic eruptions, and tsunamis, is expected to increase in the Indian Ocean region following the rupture of the once-stable Indo-Australian tectonic plate in the mid-1990s (Van Orman, 1995). A regional early-warning system cannot, by itself, guarantee safety, since the nearby Andaman Islands, which were also affected by the north Sumatra earthquake, are also

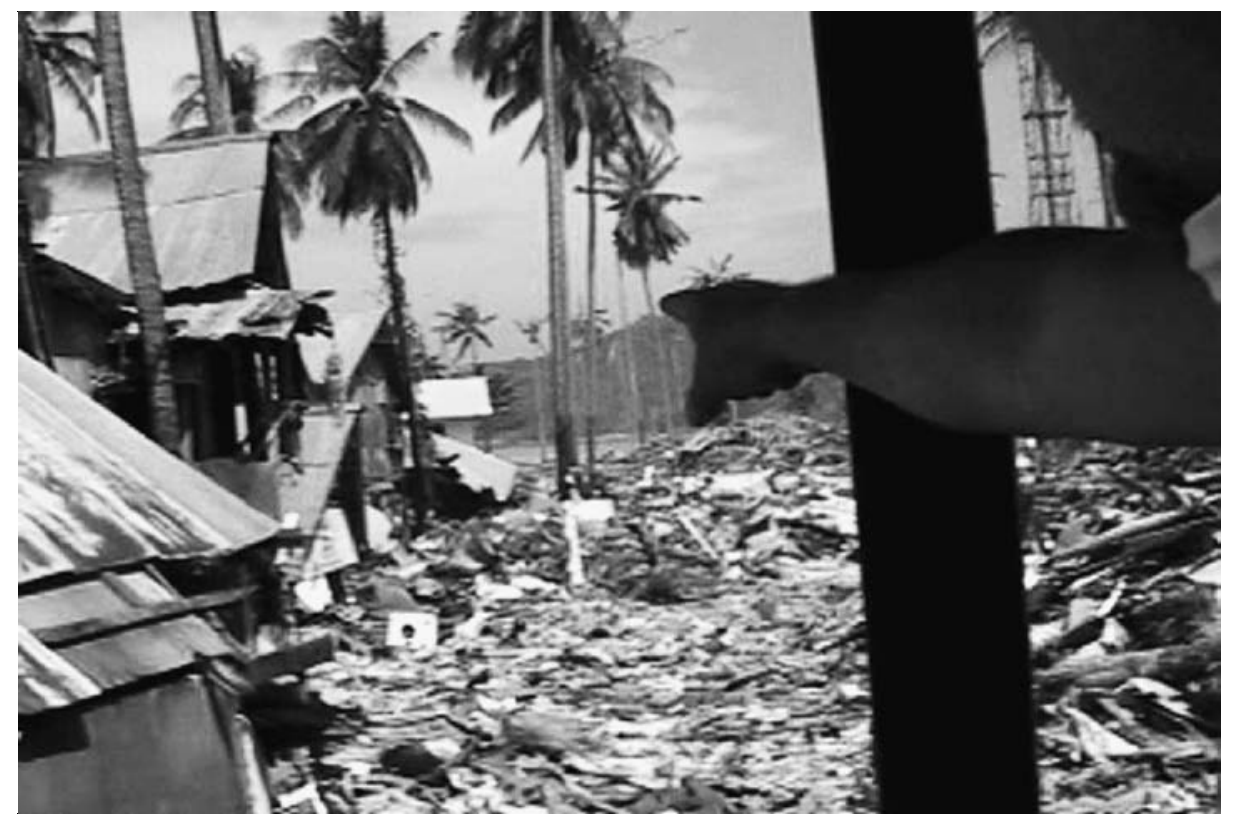

Plate 1.

After the tsunami 
becoming more prone to temblors. Resort developers must rebuild structures that can survive the worst-case scenario. In view of this, certain ideas for sustainable resort development have been suggested after research into the disaster.

\section{Resort planning}

Good planning and design of buildings can protect lives and foster a real sense of security for travelers and host communities. It is obvious that nearly all resorts in the disaster area, even the most luxurious ones, suffered in some way from bad planning and design in terms of safety. It was not a surprise then that the tsunami doomed thousands of guests, resort employees, and local residents. Had these design faults been resolved earlier, the losses in lives and property might have been greatly reduced. In the wake of the disaster, development and reconstruction should now follow a step-by-step planning procedure that encompasses site concerns, foundations, structural systems, architectural designs, and building services and landscaping) These measures can ensure the safety of buildings in all aspects. If we are to learn from the tsunami experience, the following procedure (Figure 1) may serve as an example for us to follow.

\section{Site sensitive planning}

Resort planning should be site sensitive. Investigations of topography, geology, types of foundation rock, direction of waves and wind, and other environmental factors all need to be considered. For instance, resorts directly facing the sea received the brunt of the tsunami (Figure 2), whereas those situated on the outer edges of bays, away from the focal point of the wave, were the least disturbed. The curvature and angle of the seabed determined which specific locations were severely affected. If the natural position of potential resort sites and the coastal undersea topography had been closely examined beforehand with a suitable wave-impact study, the degree of damage could have been greatly minimized.

Most of the deaths and injuries were sustained when people were hit by fast-moving debris or became trapped under the jetsam (Plate 2). The most lethal debris consisted of low-cost building materials, especially the corrugated sheet metal used to build shanties, as in Phi Phi's Tonsai beach district. Instead of ramshackle construction in crowded quarters, small businesses such as shops, bars, and guesthouses, should be

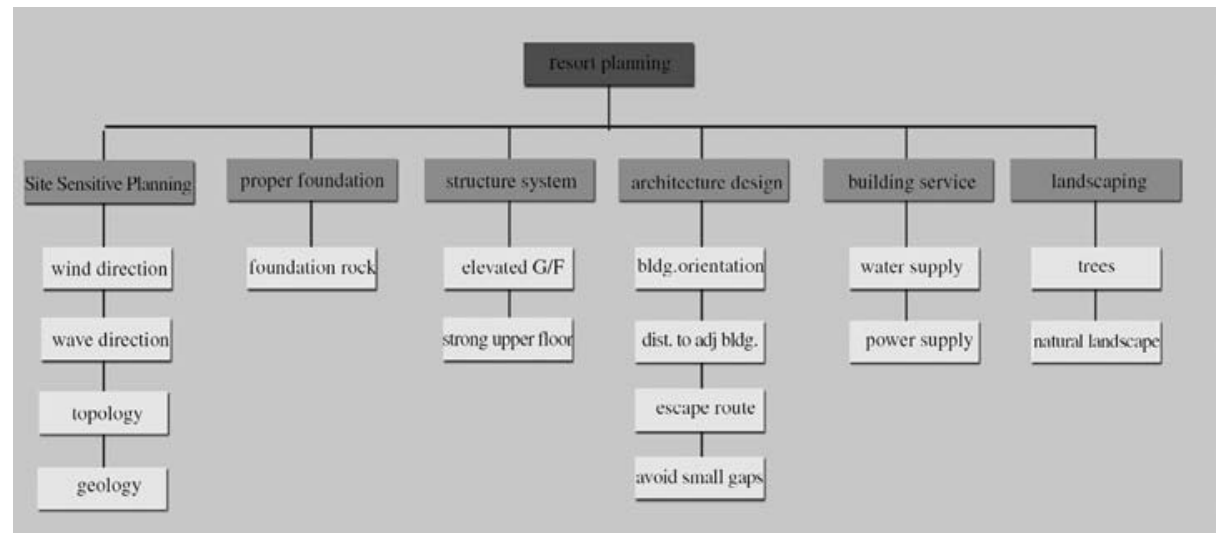

Sustainable resorts: the 2004 tsunami

431

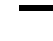


DPM

15,3

\section{2}

Figure 2.

Impact of the wave on different positions of the coast
Plate 2.

Floating debris injured or buried victims. Collapsed sheet-metal walls and roofing were lethal
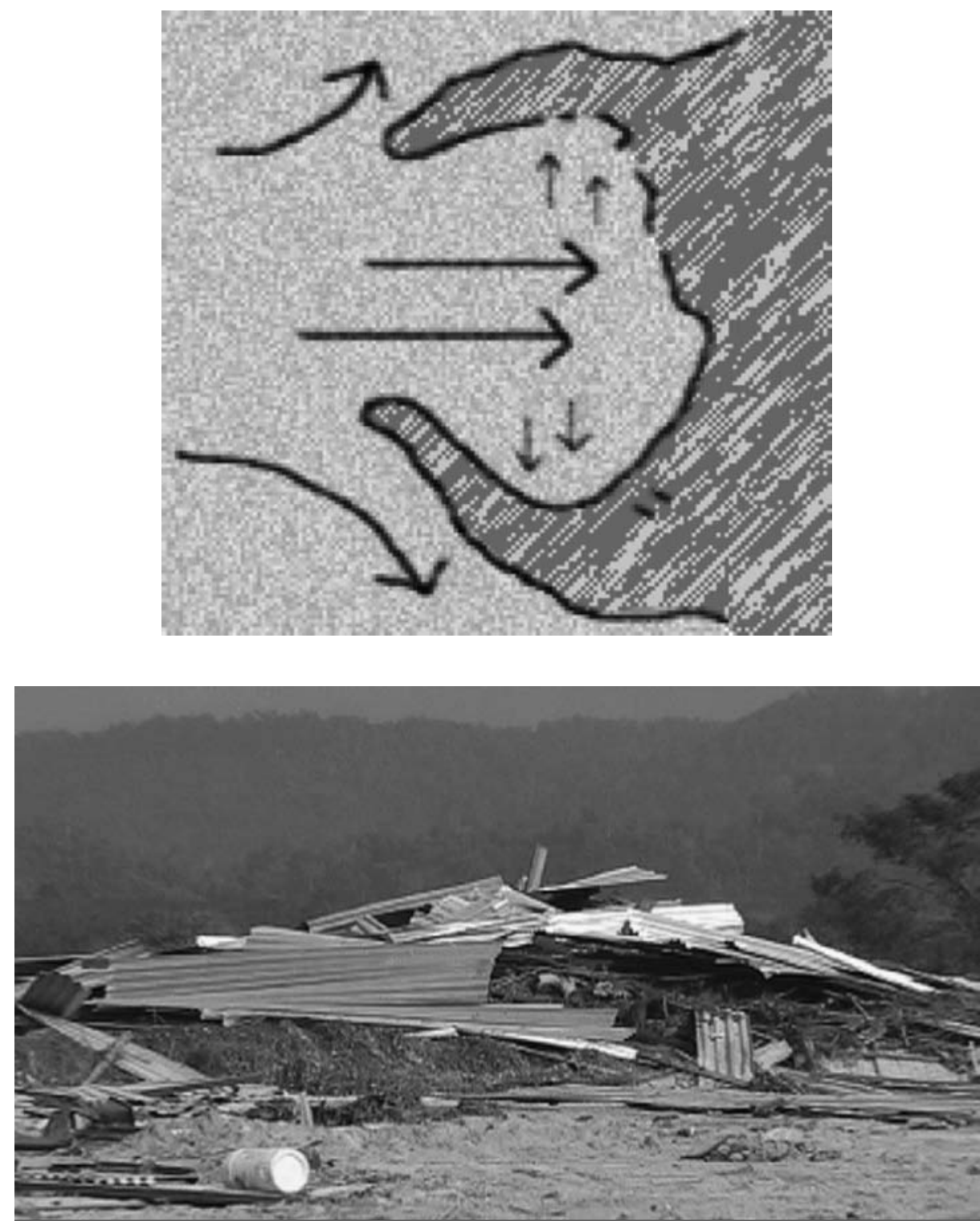

allowed to lease retail spaces in well-designed markets, preferably new structures to be built by developers or subsidized by the government. These markets should be located on lower slopes at least six meters above the high-water mark. Elevated boardwalks, linking beaches, hotels and shopping areas, would make it convenient for tourists to access hillside markets and escape the flooding to reach higher ground.

Apart from a suitable site location, it would also be useful to provide physical protection for the site. The use of offshore barriers or dykes and walls are options that 
are appropriate and economically feasible for reducing the wave energy, and thus impact, on the structures (Figure 3).

\section{Proper foundation}

Resorts and hotels were often built along the lowest-lying areas of the coast for the convenience of beach access. Nevertheless, such areas are the most prone to wave action and flooding. The low-density characteristic of sand was especially dangerous, due to its loosely packed foundation. In Patong-Phuket, Khao Lak, and KoPhi Phi, improper foundations led to the felling of resort buildings (Plate 3).
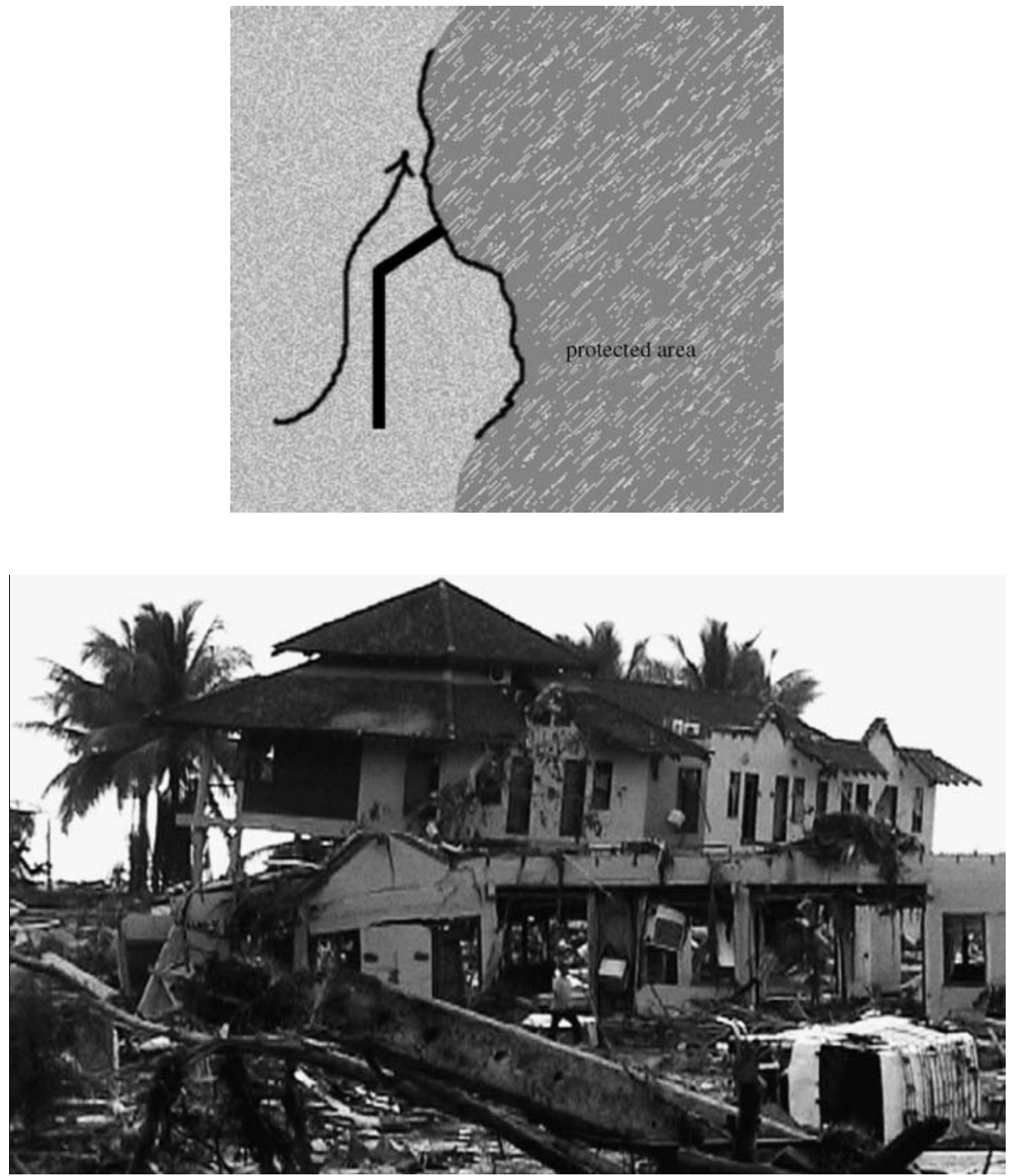

Sustainable resorts: the 2004 tsunami

Figure 3.

Physical protection coastline development
Plate 3.

Beachside hotels took the full impact of the wave. This Khao Lak hotel was lifted off its foundations 
DPM

\section{5,3}

434
On the contrary however, a group of Phi Phi resort buildings a few meters above sea level survived the disaster (Plate 4). It was obvious that an inland rock bed provided a firm foundation for these buildings to withstand great force. Zoning and land-use rules for resort districts in accordance with the contours of the land and tidal hydrodynamics should be developed. The creation of guidelines for land use will require further studies and extensive discussions by architects, building engineers, construction companies, hotel management, and government planners and regulators.

The location of foundations is extremely important, since it determines the strength of structures anchored to the soil. Additional downward force to anchor resort buildings strongly into the soil could be made possible by tension lines, soil nail, and other kinds of soil anchor (Figure 4). To further enhance a structure's durability over time, natural and artificial means of protection or foundations could be used to help prevent the displacement and slide of buildings.

\section{A proper structural system}

Structural damage to ferro-concrete structures and big wooden posts, especially in the larger hotels, was often not as devastating as the exaggerated news reports suggested. Many big hotels suffered only superficial structural damage, such as broken glass windows and interior damage, and could be renovated and reopened. Demolition was not necessary, especially in buildings where the ground floors were devoted to open-air facilities such as cafes and spas, which did not obstruct the floodwaters (Plate 5). "Wide and shallow" should be a ground rule for large structures, permitting floodwater to simply pass through unobstructed rather than constricting its flow and causing it to gain speed and rise higher.

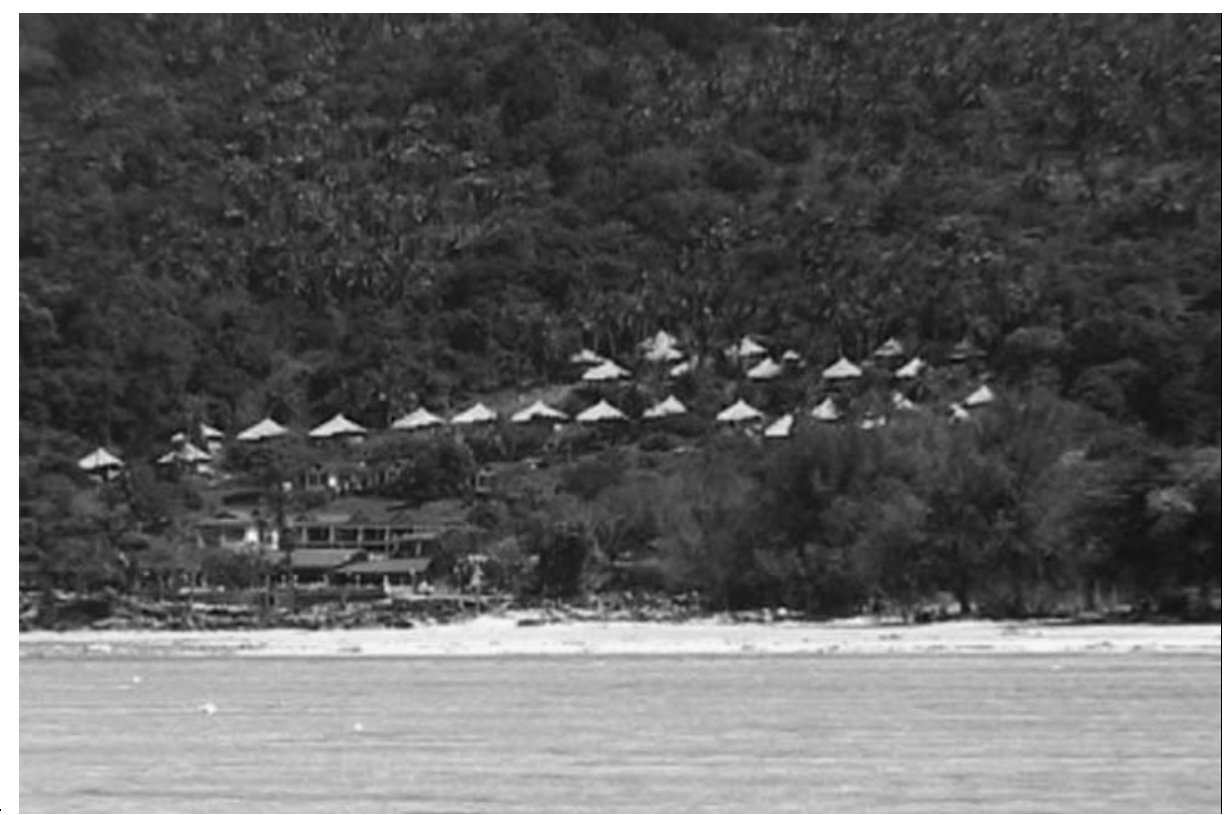

Plate 4.

A Phi Phi resort that survived was a few meters above sea level 


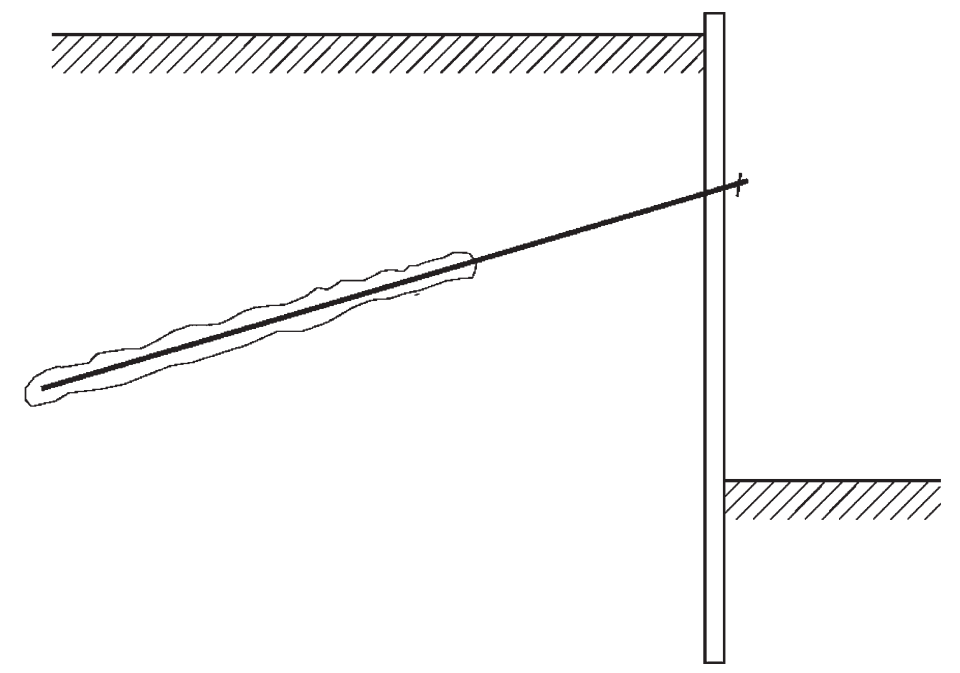

Sustainable resorts: the 2004 tsunami

Figure 4.

Soil anchor

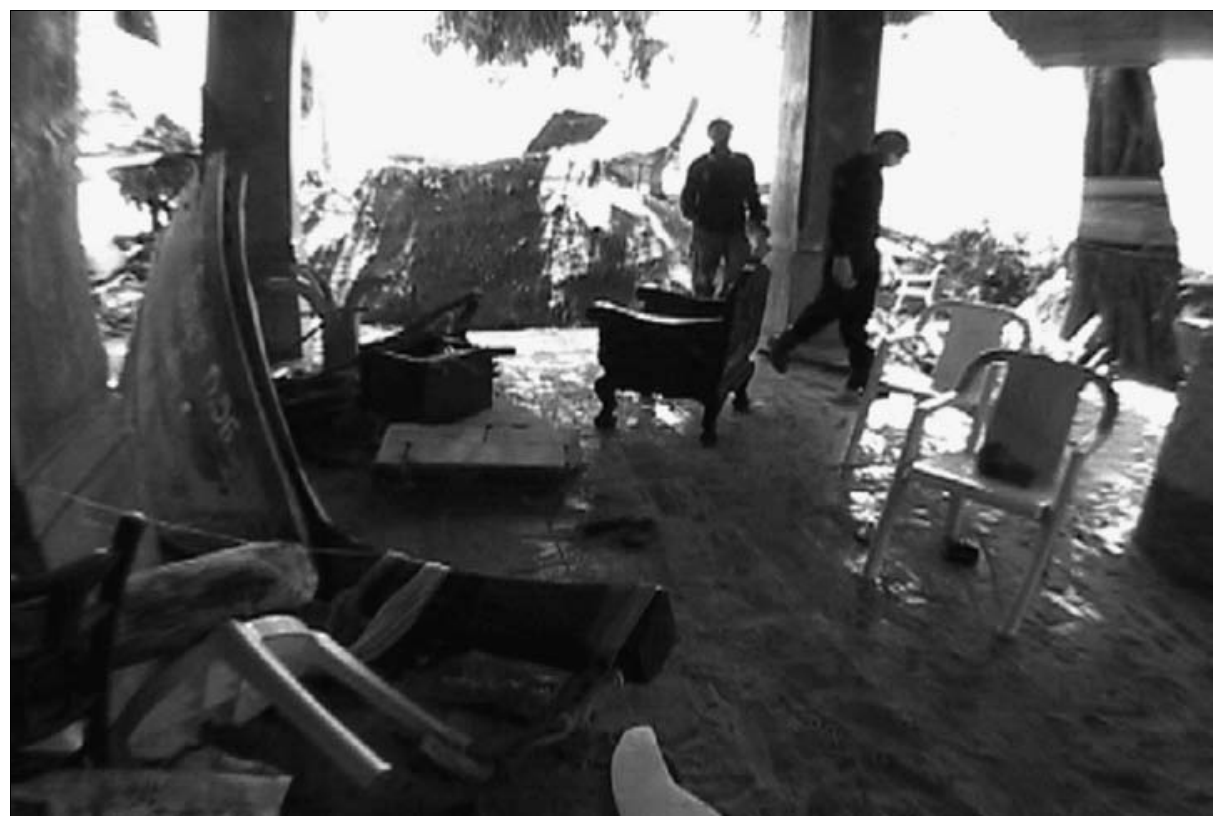

Plate 5.

The wooden posts of the banyan tree lobby in Phi Phi survived even after being hit by a boat because the ground floor was open, allowing wide and shallow flood flow

On similar principles, traditional stilt houses of the indigenous Chao Le, or "sea gypsies" along waterways survived even great tide-driven waves (Plate 6). A large force of impact was prevented by their tiny pillars. Waves simply passed through without damaging the house itself. On the other hand, houses built directly on the ground received the full force of the wave when it struck and retreated. These houses were pulled off their foundations. 


\section{DPM}

15,3

\section{Plate 6.}

Stilt houses and long-tail boats survived waves along rivers and mangrove networks

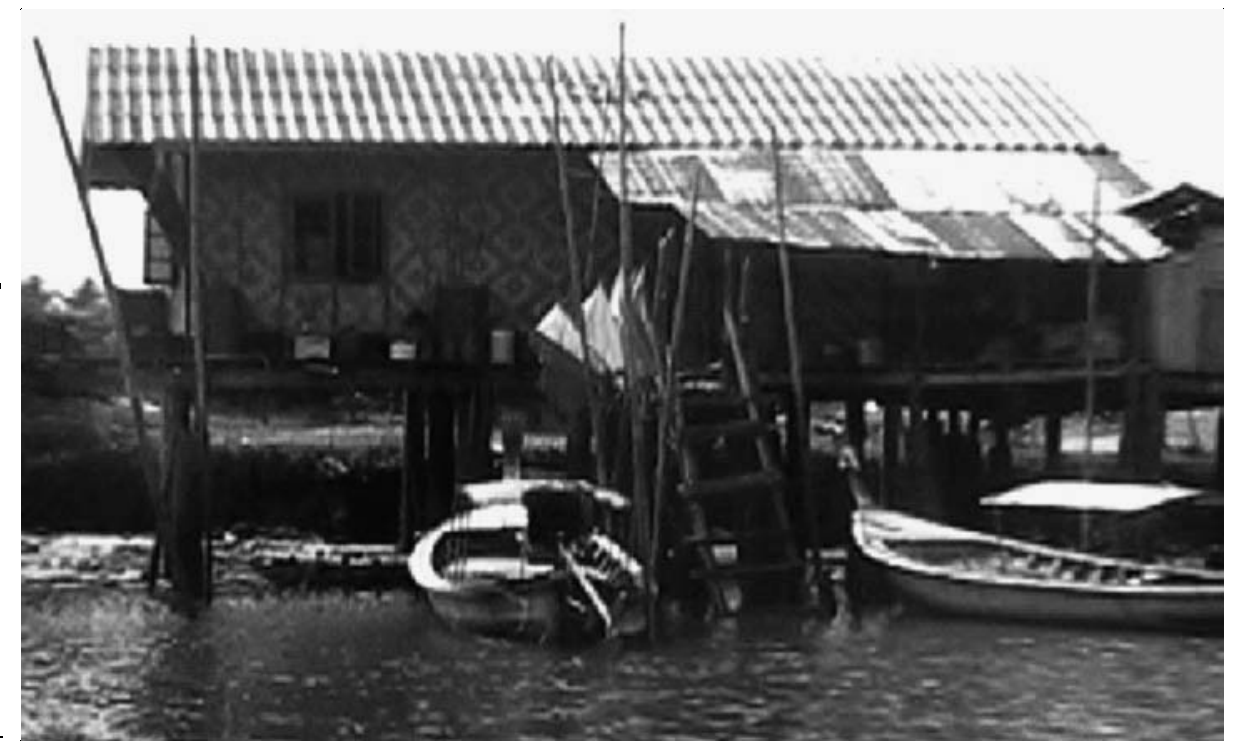

A much more detailed study is needed to better understand how structural systems can be designed and situated to withstand lateral wave impacts. Some sub-topics for further research include:

- the shape of columns (round, square, or rectangular), and the direction of the column in relation to incoming waves (flat or diagonal);

- the degree of impact on wall systems (force applied at different heights), and again the placement issue (diagonal vs fronting the sea); and

- natural and traditional built models of flood-resistant structures, like the root and trunks of banyan trees and stilt-house building methods.

Low-density services like spas and waiting areas should be placed on the ground floor with a minimum of walls or partitions. Elevation can save a building from collapsing (Figure 5).

In contrast, management and security functions such as communications centers, safety deposit boxes, reservation desks, and offices should be relocated to the upper floors so that they can still function during and after the disaster. This step will help maintain emergency management functions during disasters. Back-up power generators should also be moved to roofs or upper floors to prevent flood damage to hardware.

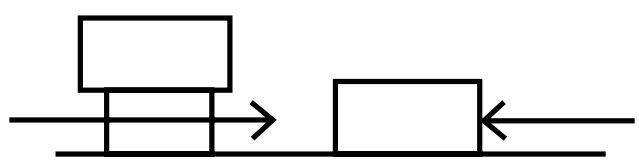

Figure 5.

Note: Left: wave passes by thin posts without great damage to the building. Right: direct impact from a tidal wave occurs when building is at the ground-floor level. 
Raised structures on stilts give an advantage to resorts for reducing a wave's impact in each section. Bellows could be a mitigation approach if stilts are not practical. These plan diagrams (Figures 6 and 7) show the structural organization for reducing a wave's impact on the more critical structural elements. Caution should be exercised in those areas with pedestrian congestion, such as corridors, elevator entrances, and walkways, which should be shielded or raised above ground level.

The use of heavy construction as opposed to light construction is less vulnerable not only to typhoons but to tsunami waves as well. Apparently, heavy timber and ferro-concrete structures had the best chance of surviving the impact of waves. It is important to ensure that there is consistency and balance between tsunami-resistant construction and structural requirements of natural force such as earthquakes, which sometimes run counter to these principles. A careful equilibrium should be achieved.

\section{Proper architectural design}

\section{The orientation}

To enjoy a full view of the waterfront, resorts are usually oriented with the wider side facing the sea. Unfortunately, this orientation makes buildings more collapsible. During the disaster, buildings that received less damage tended to have a smaller
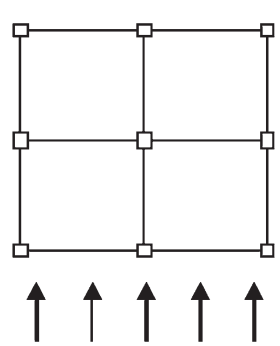
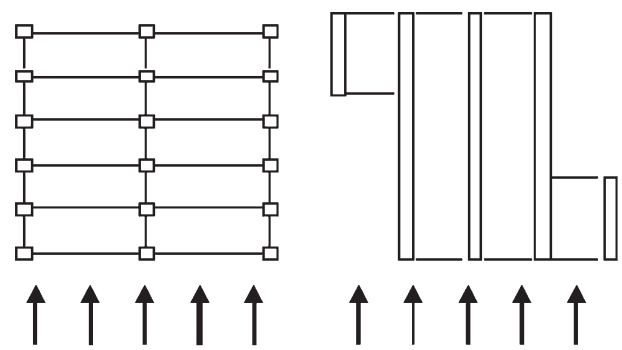

Note: Utilization of rigid frame or cantilever column action as lateral resistance system on exposed face reduces obstruction to flow while shear wall, bracing, and frame action all remain options along lines parallel to flow.

Sustainable resorts: the 2004 tsunami
Figure 6. Structural organization allowing minimal resistance to the flow of water

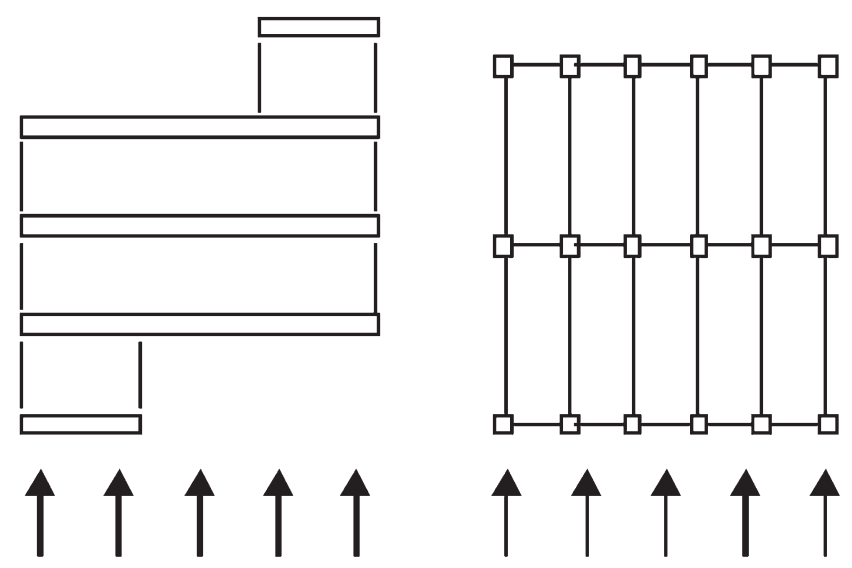

Figure 7.

Structural organization resulting in greater resistance to flow, which resulting in greater impact forces 
DPM

15,3

438 surface area facing the water. A larger tidal force was received when a wider surface was presented (Figure 8). The extraordinary destruction seen in parts of Khao Lak seemed to indicate an exponential increase in force received relative to the surface area. Wave-tank model studies should be made available to resort designers in the future.

\section{Distance from adjacent buildings}

The funnel effect, naturally formed by bays or artificially by building density, vastly increased the speed, strength, and killing power of the flowing water. Narrow spaces between buildings forced the flowing water to pick up even more speed and rise higher. Small openings under walkways and floor-supports trapped victims, who were thrust downward by the mass of water. Doors that opened inward allowed the water pressure to force them open easily. Hotel rooms, once filled with water, had no escape routes, which could have been provided by ceiling-height windows or skylights.

If a wider street or passageway had been provided in between buildings, the gap condition would have changed from semi-permeable to permeable. The mass of water would not have been intensified nor passed at such a high speed. Also, the work of emergency services would have been made easier, since debris would not have been stuck and piled high in narrow passageways (Plate 7 and Figure 9).

\section{Escape routes}

The lack of escape routes to higher elevations was a major factor in the high death toll (Plate 8). Wherever beach-goers could rapidly access outdoor stairways to balconies, they had a good chance of surviving the flood, even in cases of very short notice or of being swept along by the wave. Tsunamis and strong tides can move very quickly, outpacing beachgoers, and reducing the odds of horizontal flight away from the waves. The best direction is upward.

Emergency escape should always be prioritized in the highest rank for the design of buildings. Proper escape routes should be designed for all kinds of emergencies. Raised boardwalks along the beaches could be installed so that users will always have a chance to escape to the upper levels of hotels or the hillsides. This simple method, which is inexpensive to install, could save thousands of lives.

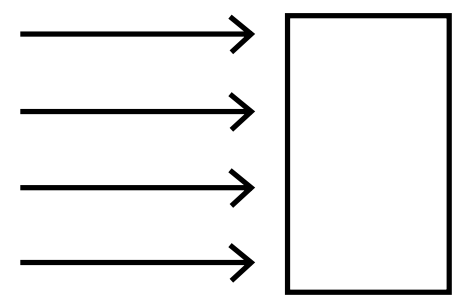

Figure 8.

A larger surface receives a greater force 

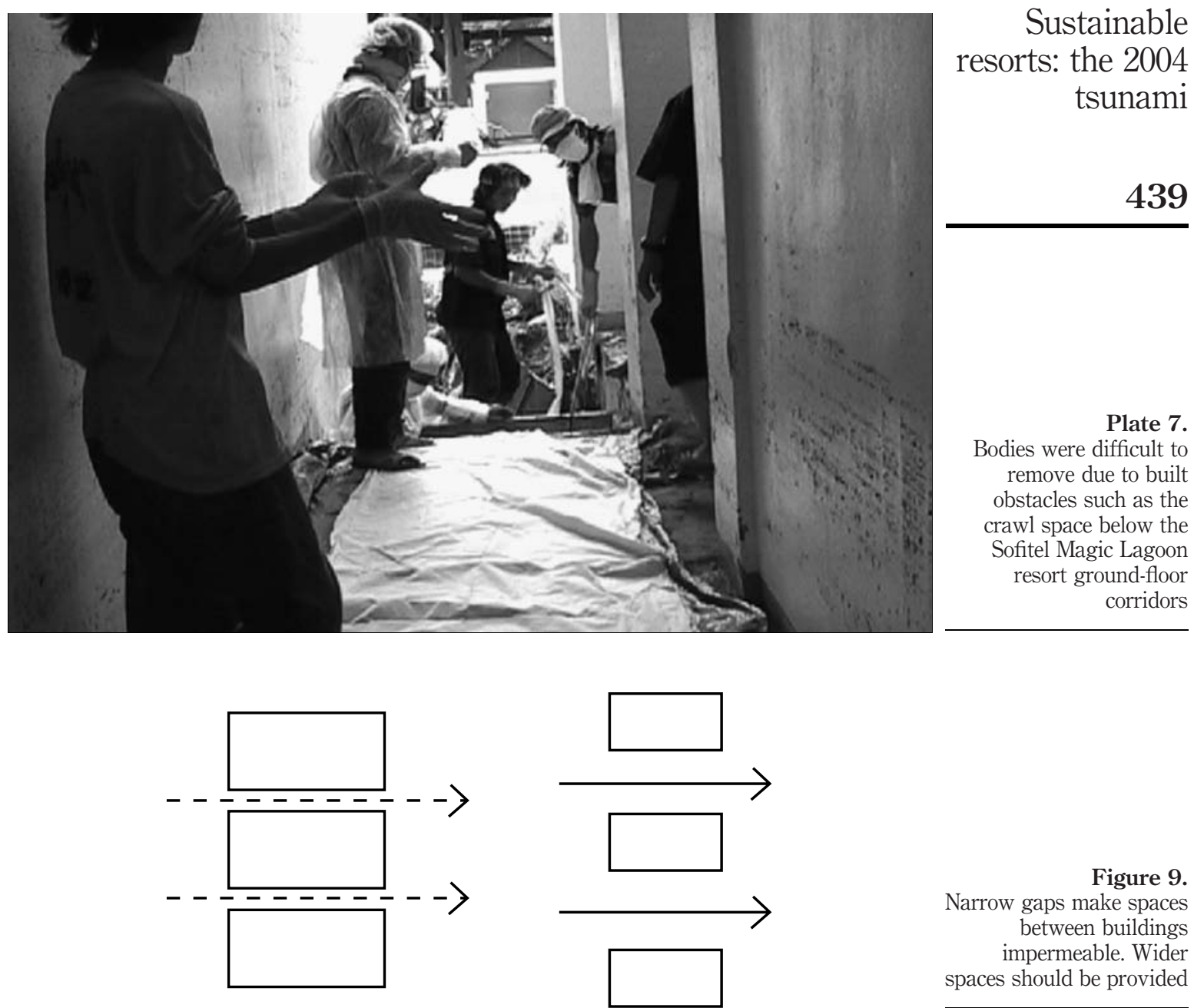

Plate 7.

Bodies were difficult to remove due to built obstacles such as the crawl space below the Sofitel Magic Lagoon resort ground-floor corridors

The international community has put great emphasis on developing a tsunami-warning system in the region. The warning system, however, could have the unintended effect of causing people to flee to unsafe positions, for example, along low-lying roads or in cars, which are highly vulnerable to wave action. The warning system should therefore include specific and well-rehearsed escape routes for each resort and neighborhood in the flood-prone areas.

\section{Avoid small gaps}

Design flaws like narrow gaps between the ground and the base of buildings presented hidden dangers (Figure 10 and Plate 9). During the tsunami, many people were trapped or stuck between these gaps and died because they were unable to crawl out. Narrow or low inlets should be covered with metal grills to prevent the trapping of people or 
DPM

\section{5,3}

\section{0}

\section{Plate 8.}

Beachgoers were drowned because there were no escape routes to higher levels. This Khao Lak hotel lacked outdoor staircases to higher ground and upper-floor balconies that could have saved lives

Figure 10.

Plate 9.

Narrow and low spaces trapped people underwater
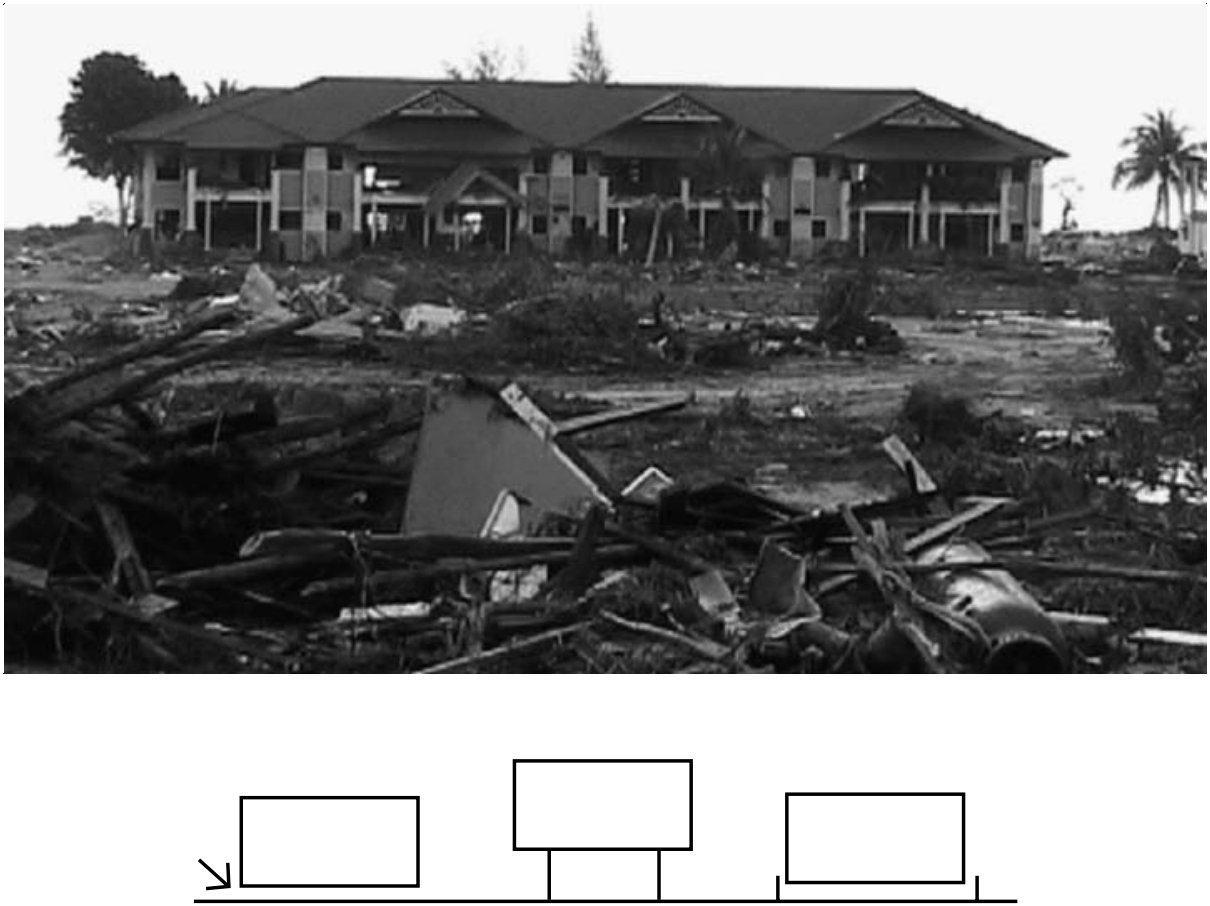

Note: Left: narrow gap traps people. Middle: elevated gap allows people to pass through. Right: blocking gaps

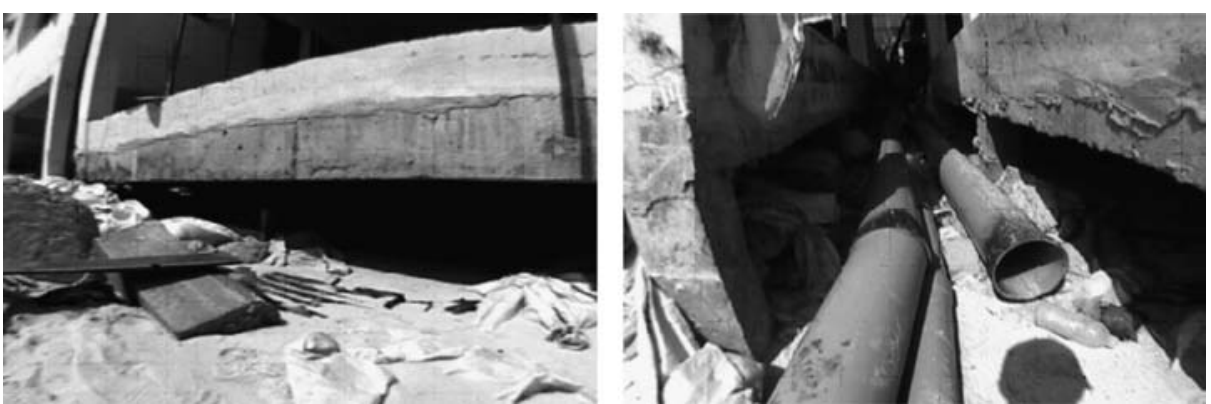

objects in these spaces. Grills allow ventilation while providing safety. An alternative is to raise the gap between the ground and the base of buildings to allow water to pass under without trapping people or debris.

\section{Building services}

Drinking water and electrical supply were found to be woefully insufficient during and after the disaster. Since, the arrival of the tourism industry two decades ago, the 
region's freshwater resources have been wasted, mainly as flushing water for tourists. It is obvious that the planning and back-up building services were not properly provided for during design stage. It was difficult for the victims to find even a single drop of fresh water after the tsunami. Electricity was totally cut off and emergency services experienced great difficulties.

\section{Water supply}

The tourism industry contributed to the deaths of local fishermen and shopkeepers by literally flushing fresh water down the toilet. The massive waste of fresh water resources by hotels and restaurants has drained lagoons and creeks, thereby transforming the remaining lowlands into sites for building more houses and shops (Plates 10 and 11). In Khao Lak, the tsunami moved "like a snake" through dry creek beds and lagoons, demolishing everything in its path. In contrast, areas surrounded by healthy lagoons and rivers, like Krabi town, were protected by these natural features from the wave and sustained much less damage. Lagoons, creeks, klongs (manmade pools, canals), and other water channels need to be restored as a self-regulating system that can apply counter-pressure on floodwaters rushing in from the sea and absorb overflow from the sea or rivers.

To prevent the same situation from happening, it is necessary to restore the lagoons and waterways. Freshwater pressure reduces wave shock. Mangrove forests block and absorb floodwater. Fresh water should no longer be used for flushing. Recycled waste water should be considered as a source for non-drinking functions. A regional study of patterns of settlement by the indigenous Chao Le, and their use of mangrove forests as natural barriers, should be conducted to better understand the relationship between the natural and built environment.

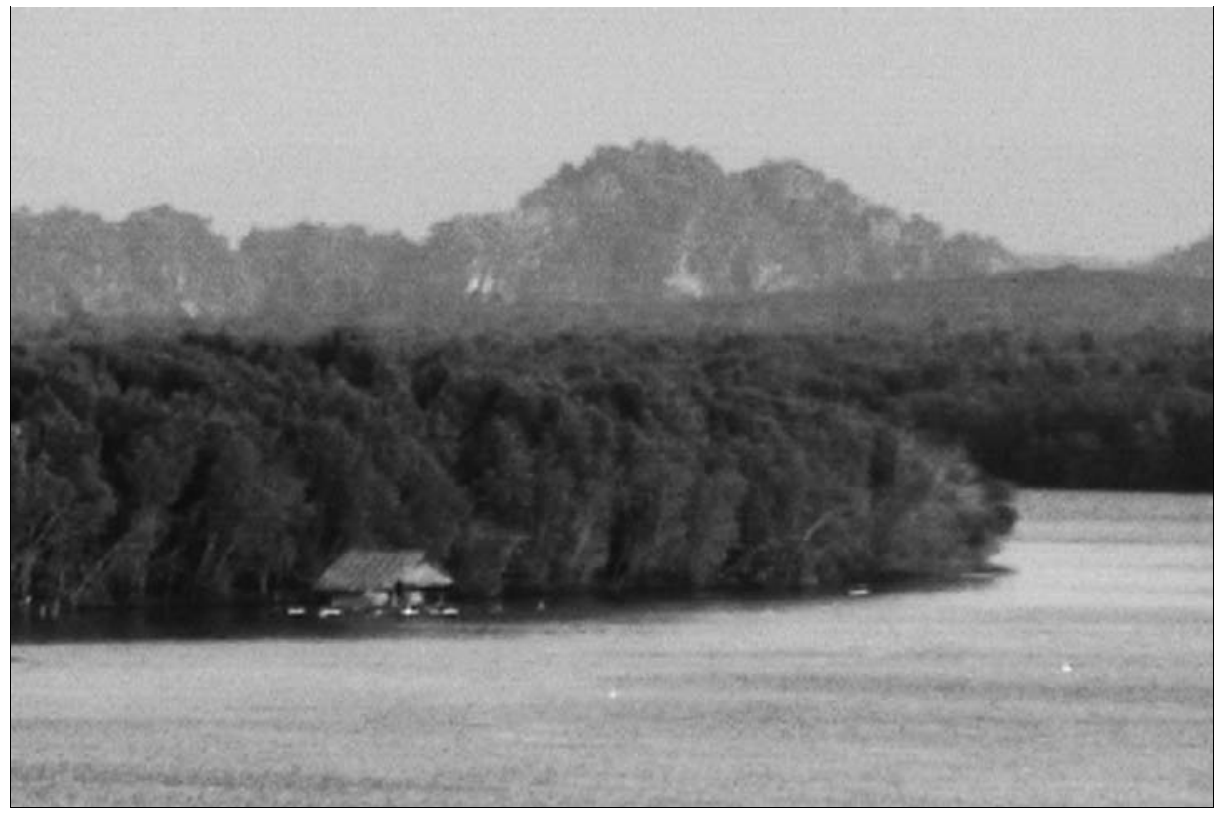

Plate 10.

What if the local fresh water source has run dry? Treat and recycle waste water from hotels 


\section{DPM}

15,3

\section{Plate 11.}

Construction drained the lagoons, and fresh water was flushed from toilets and showers into the sea

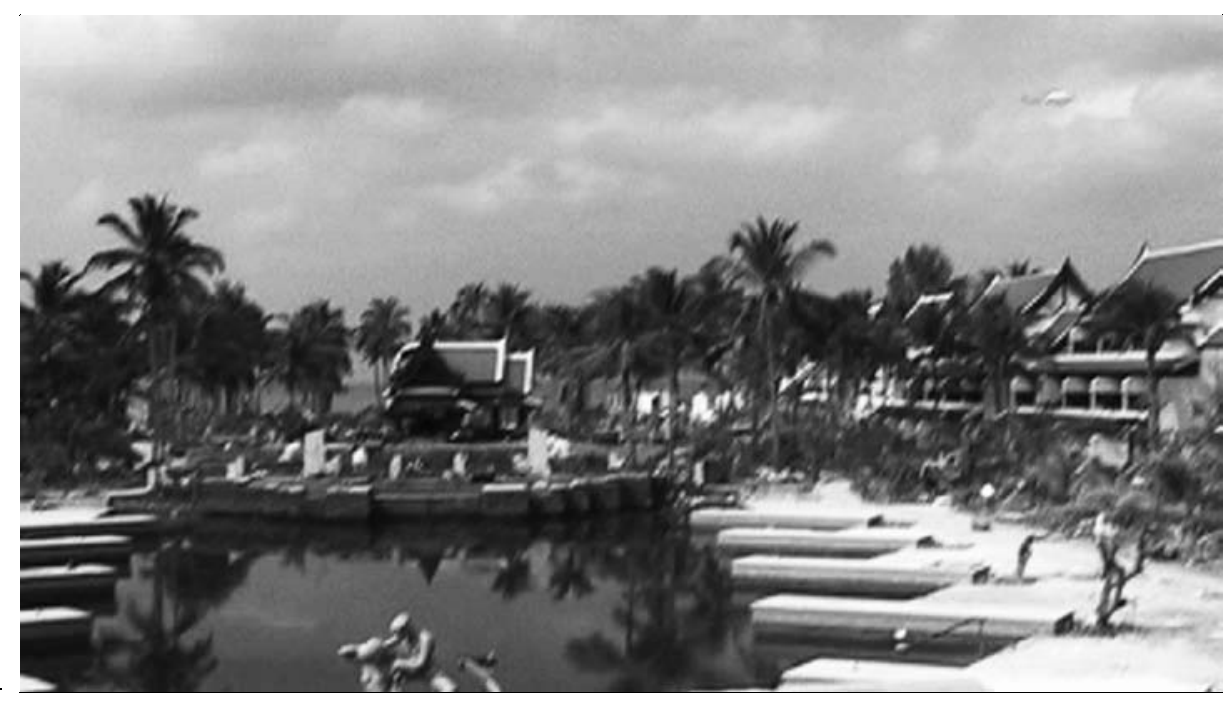

\section{Electricity}

The major resort complexes lacked co-generation power plants on their grounds for generating electricity. When power lines were destroyed by the tsunami, the entire coast suffered a blackout of lighting and communications, adding to the chaos for at least one week (Plate 12).

Co-generation of electricity is a vital emergency service, which can supplement public power during peak use hours. Hardware should be installed above ground to ensure that power is not cut off completely during a crisis. Mobile phone base stations should also be linked to local co-generators to ensure that communication is possible.

\section{Landscaping}

The occasional banyan, with its many trunks and aerial roots, saved many lives, allowing people to find support against the water flow and climb above danger (Plate 13). Palms, which are visually attractive, are harder to climb and have no branches. The planting of sturdy, branching hardwoods in resort areas is a "must-do." Innovative tensile structures and flexible platforms on larger trees could be designed as a form of recreation to encourage people to climb, as well as a safety measure.

Natural landscapes at higher levels can also provide safety platforms during tsunamis and floods. Landscape design should be incorporated as a safety feature in the master planning of resort development (Plate 14). It can help restore the balance between the natural and built environments.

\section{Learning from tradition}

The best way to prevent massive casualties in natural catastrophes is passive defense, mainly through the placement and design of buildings. Electronic warning systems are workable only if there exist escape routes close to every hotel and neighborhood. 


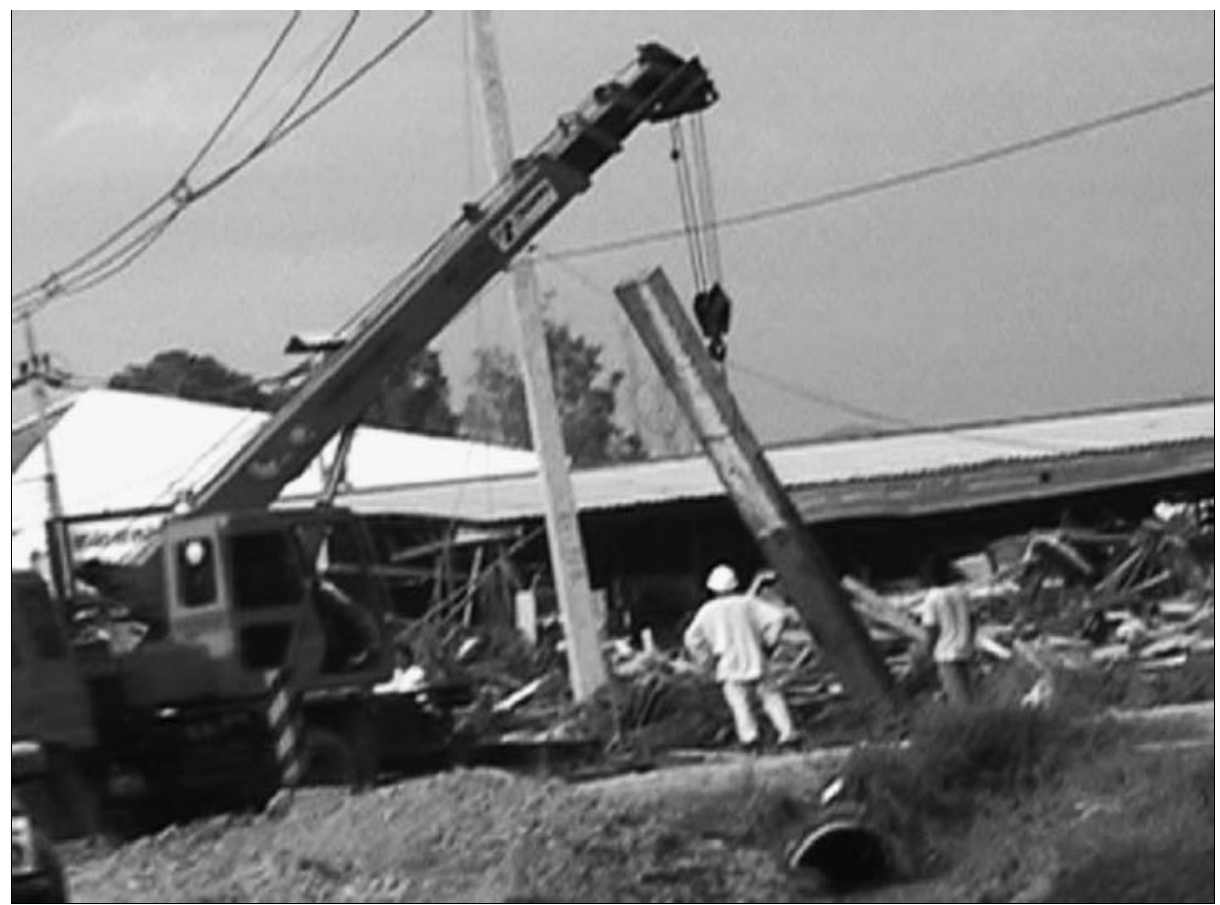

Sustainable resorts: the 2004 tsunami 443

Plate 12. A power outage led to chaos and lawlessness. Debris tore down power lines

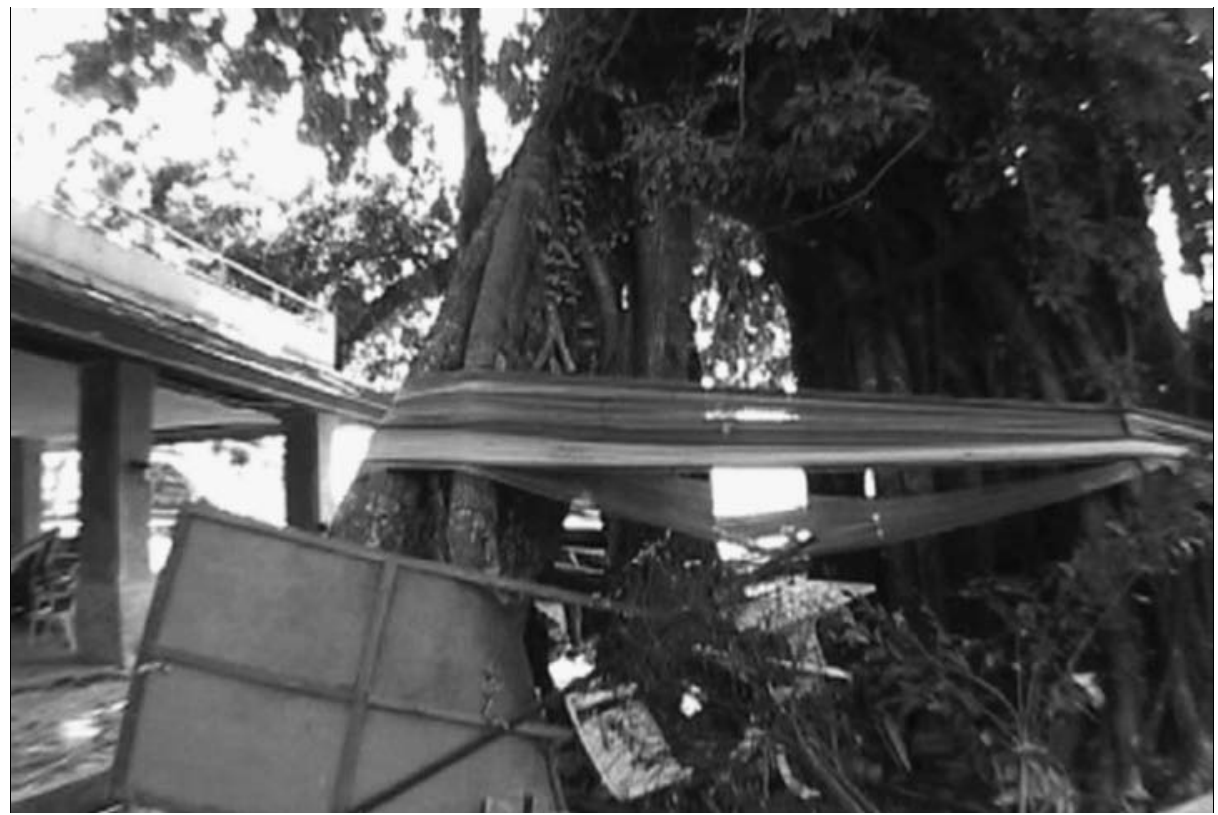

Plate 13.

Multi-branched trees with aerial roots proved to be better at saving people than eye-catching palms 


\section{DPM}

\section{5,3}

\section{4}

\section{Plate 14.}

Landscape design can be a part of a built-in safety system

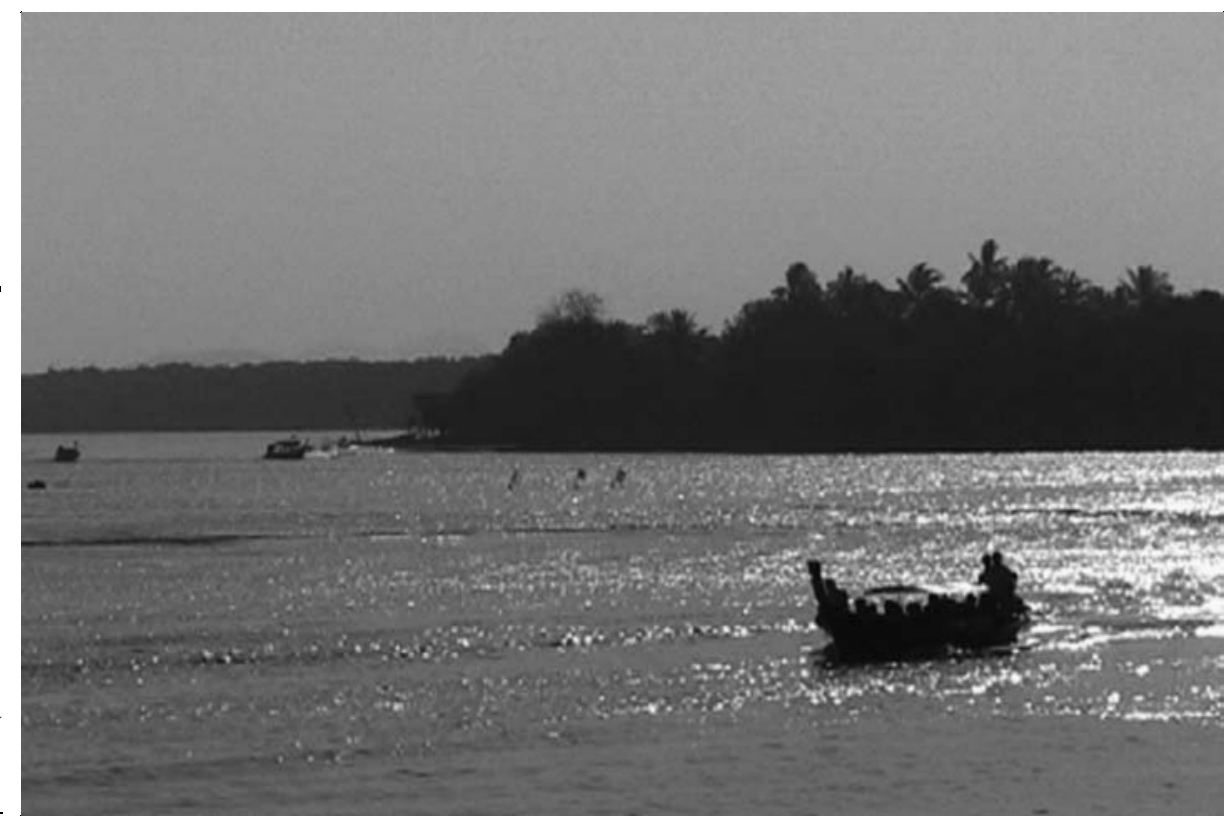

The tourism industry, despite its technological advances and sophisticated building methods, turned out to be the most vulnerable sector along the Thai coast. Resort designers have much to learn from the vernacular architecture of the coastal region.

Chao Le: the sea gypsies

The Chao Le, or sea gypsies, are the indigenous inhabitants of the Thai coast. The predominantly Muslim sea gypsies are a people who have survived "at the edge" of land and water for many thousands of years. Traditionally, they lived in stilt huts along rivers and lagoons, structures designed to withstand the tides and monsoon floods. Pillars are also necessary to keep away reptiles and insects, as well as to avoid the stench of waste. The native long-tail boats are crucial for their livelihood (fishing and trading). To pursue their sea nomadism, a Chao Le family often has several distantly spaced huts to increase its foraging range. The three major clans Uluk-lawoi, Morglen, and Morgan - span the coast across Malaysia, Thailand, and Myanmar, respectively. Their local knowledge is extensive, although they are subject to the regulations of their host nations. Their settlement patterns in relation to the features of the natural environment should be studied more systematically.

\section{Ethnic Chinese}

Two distinct groups of ethnic Chinese form a majority in urban Phuket and a business-oriented minority throughout the coastal region. The first group is the Malay Chinese, whose ancestors were seafarers and merchants from Penang, Malaysia, which has been a center for trade with China for hundreds of years. The second group are the Hokkien Chinese, descended from the tin miners who emigrated from Fujian Province in the late nineteenth century, to extract tin from the Phuket area (Notably, tin mining 
was the first industry to disrupt and pollute the lagoon environment). The ethnic Chinese established towns along the coast using a Portuguese-Chinese architectural style, which includes neo-Baroque stand-alone buildings and row houses. Their towns were usually built on hills and higher ground above the flood line.

Sustainable resorts: the 2004 tsunami

\section{Non-sustainable development of the tourist sector}

Tourism developed as an industry along the coast starting in the late 1970s. Owing to the demand for scenery rather than safety, the tourist trade has been the least environmentally sustainable form of human settlement on the coast of Thailand and the least integrated into the natural ecology. A huge challenge lies ahead for planners, architects, and resort management to integrate tourist facilities into the natural environment, particularly developing models of environmentally sustainable architecture appropriate to the coastal lagoon topography. In contrast to the established communities of Chao Le and ethnic Chinese, the tourist resorts had major vulnerabilities to disaster:

- Buildings were sited in environmentally hazardous zones, like along beaches prone to flooding and tsunamis.

- Tourism attracted dense concentrations of transient people - foreign visitors and migrant workers - who had no long-term relationship with the area or the established communities.

- Resort complexes and clusters, as non-permanent groupings, lacked the leadership and communication networks of the more resilient established communities, leading to the collapse of communications after the tsunami.

- Hotels and upscale restaurants were dependent on imported goods, services, and power, isolating it from local communities, which produce their own food, transport, and energy resources. (Stranded and injured visitors often had to get first aid, food, water, shelter and transport from local fishermen and shopkeepers rather than from tourism operators).

- Owing to the very high tourist demand for flush toilets and showers, resorts depleted the water resources of the coast, causing the drainage and pollution of lagoons and rivers, which had protected the land. Drainage spurred a building boom on lowlands, which increased population density in flood-prone areas.

\section{Action plan: major response for resort (re)construction}

Learning from local traditions, development in the past adapted to site conditions to avoid damage from natural disasters. In contrast, more recent developments did not follow the knowledge and traditional skills of the indigenous community. Tourism developers were shortsighted and money-oriented, and safety was hence not a priority. To avoid a repeat of the tragedy, action must be taken.

Response to site - relocate small businesses on hillside market areas

Elevated boardwalks can link to arcades or markets containing guesthouses, cafes, bars, boutiques, and souvenir shops. These multi-tenant facilities should be built of reinforced concrete instead of easily removable materials such as sheet-metal. These small modifications will also retain the atmosphere and cultural life of resort towns. The removal of small businesses from existing sites will require a "land swap" system similar to the reallocation procedures used in Japanese islands with active volcanoes. 
DPM

15,3

446

Response in foundation and structure - correct the design flaws in larger structures Architectural engineering plans should include a hydrodynamic study of each building complex in relation to the sea, inland waters, and neighboring structures. Narrow openings in foundations and crawlspaces should be covered with cement-coated wire mesh to prevent the trapping of flood victims. Deflectors, channels, and outlets can prevent the rise of floodwaters and divert water flow to surrounding waterways.

Response in architecture - introduce escape routes to elevated areas, safer rooms

Elevated boardwalks on reinforced pillars, accessed by wide staircases and connected to higher ground or upper stories/balconies of hotels, should be installed within a three-minute run from the high-tide mark of beaches. On a day-to-day basis, these boardwalks can serve as scenic viewing platforms and cafés, with vendors at the ground level, and should therefore be attractively and unobtrusively designed. Hotels should install outdoor staircases linked to balconies, preferably in a series of levels up to the third floor.

Hotel rooms can be modified to help guests block or escape from floodwater. Outward-opening doors should be installed to prevent the quick entry of water. The exterior frames of windows should be equipped with deflectors to prevent pressure build-up against the glass. Higher windows or sunroofs should be installed to allow guests to escape the rising water. Refrigerators, television sets, and other objects that can pose a danger when washed away should be bolted to the floor or wall.

\section{Response in building services - restore the waterways and using co-generation}

Lagoons and creeks should be restored by recycling wastewater from hotels (after treatment) and by restrictions on usage. Showers and toilets should use only recycled water, which of course should be properly treated and biologically safe. In addition, manmade waterways such as klongs, ponds, and large fountains should be installed lower than adjoining populated areas to serve as channels to decrease the water pressure along the broad wave front. A climbable metal grill barrier between the beach and lagoons can prevent beach-goers from being swept inland. The landscaping plan should include tree planting and "island" mounds to maximize the number of escape routes. Hotels should also have fleets of small boats to ply lagoons.

Major resorts should be required to have electrical co-generation facilities on higher ground that connect with hotels and restaurants above the second floor level. Gas-powered plants should be used to complement public power at peak hours. The equipment must be maintained and staff must be familiar with the generation technology. These secondary power sources should also be linked to mobile phone base stations to ensure that communications are not disrupted after the back-up batteries run down.

Response in landscape - plantation of trees and incorporation of natural landscape A balance and proper relationship between humans and nature has always been important. It provides a pleasant environment, and at the same time offers temporary shelter in cases of emergency. Linking up resort development with the natural landscape is a new challenge for resort designers. Landscape design should also be carefully considered to fit site layout. 


\section{Conclusion}

The tourism industry cannot go back to shortsightedness and fast money because disaster will strike again. As this unfortunate experience has shown us, sustainable architecture could mean the difference between life and death. Careful consideration should be given to site conditions, structural issues, architectural issues, landscaping, and even building services. More studies are needed in each of these areas. A safe and pleasant atmosphere will, in turn, draw more people to enjoy nature, thus benefiting the economic development of local communities.

\section{Reference}

Van Orman, J., Cochran, J.R., Weissel, J.K. and Jestin, F. (1995), "Distribution of shortening between the Indian and Australian plates in the central Indian Ocean", Earth and Planetary Science Letters, Vol. 133 Nos 1/2, pp. 35-48.

\section{Further reading}

Besana, G.M., Ando, M. and Mirabueno, M.H. (2004), "The May 17, 1992 event: tsunami and coastal effects in Eastern Mindanao, Philippines? Science of tsunami hazards", The International Journal of the Tsunami Society, Vol. 22 No. 2, pp. 61-8.

Bryant, E. (2001), Tsunami: The Underrated Hazard, Cambridge University Press, Cambridge, MA.

Caminade, J.P., Charlie, D., Kanoglu, U., Koshimura, S., Matsutomi, H., Moore, A., Ruscher, C., Synolakis, C. and Takahashi, T. (2000), "Vanuatu earthquake and tsunami cause much damage, few casualties, EOS”, Transactions American Geophysical Union, Vol. 81 No. 52, pp. 641, 646-7.

Casale, R. and Margottini, C. (2004), Natural Disasters and Sustainable Development, Springer, Berlin, NY.

Hebenstreit, G. (1997), Perspectives on Tsunami Hazard Reduction: Observations, Theory, and Planning, Kluwer Academic Publishers, Boston, MA.

Lander, J.F., Whiteside, L.S. and Lockridge, P.A. (2003), "Two decades of global tsunamis, 1982-2002, science of tsunami hazards", The International Journal of the Tsunami Society, Vol. 21 No. 1, pp. 3-88.

To purchase reprints of this article please e-mail: reprints@emeraldinsight.com Or visit our web site for further details: www.emeraldinsight.com/reprints 